\title{
Definitive diagnosis and surgical planning of H-type tracheoesophageal fistula in a critically ill neonate: First experience using air distension of the esophagus during high-resolution computed tomography acquisition
}

\author{
Phalla Ou, MD, ${ }^{a}$ Elisa Seror, MD, ${ }^{a}$ Wael Layouss, MD, ${ }^{a}$ Yann Révillon, MD, PhD, ${ }^{\mathrm{b}}$ and Francis Brunelle, MD, PhD, ${ }^{a}$ \\ Paris, France
}

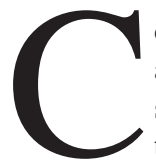

ongenital tracheoesophageal fistula without esophageal atresia, commonly referred to as H-type fistula, corresponds to a fistula between the posterior wall of the trachea and the anterior wall of the esophagus. ${ }^{1}$ The diagnosis is suspected on the clinical triad including choking and cyanosis on feeding, gaseous distension of the gastrointestinal tract, and recurrent lower respiratory tract infections. In routine practice, the symptoms are nonspecific, and the diagnosis of $\mathrm{H}$ type fistula is difficult and often delayed. The various diagnostic modalities are not entirely reliable, and fistula identification is generally elusive. $^{2}$

The present case highlights the potential diagnostic utility of high-resolution computed tomography (CT) scanning in this clinical situation.

\section{Clinical Summary}

A 3-week-old boy was transferred to our hospital for malposition of the great arteries with multiple ventricular septal defects that had been diagnosed on antenatal ultrasonographic exam. Surgical intervention consisted of pulmonary banding.

Five days after surgery, he had severe respiratory distress that required tracheal intubation and mechanical ventilation. Chest radiograph was consistent with inhalation pneumonia. He was initially stabilized with administration of antibiotics. However, the situation worsened, and high-frequency oscillating ventilation was needed because of intermittent oxygen desaturations and recurrence of pneumonia. The diagnosis of tracheoesophageal fistula was suspected because of the association of respiratory injury and gaseous distension of the gastrointestinal tract. As bronchoscopy was regarded as hazardous for this critically ill infant, we performed chest CT scanning with a LightSpeed VCT (GE, Milwaukee, Wis): slice thickness $0.625 \mathrm{~mm} \times 64$, speed rotation 0.4 seconds, pitch $0.9,80 \mathrm{kV}, \mathrm{mA}$ modulated during the acquisition.

From the Departments of Pediatric Radiology and Pediatric Surgery, University Rene Descartes-Paris V, Hôpital Necker-Enfants Malades, APHP, Paris, France.

Received for publication Nov 30, 2006; accepted for publication Jan 5 , 2007.

Address for reprints: Doctor Phalla Ou, Department of Pediatric Radiology, Hôpital Necker-Enfants Malades, 149, rue de Sèvres 75743 Paris Cedex 15 France (E-mail: phalla.ou@nck.ap-hop-paris.fr).

J Thorac Cardiovasc Surg 2007;133:1116-7

$0022-5223 / \$ 32.00$

Copyright @ 2007 by The American Association for Thoracic Surgery doi:10.1016/j.jtcvs.2007.01.003
Images were acquired simultaneously with air insufflation into the esophagus by means of the nasogastric tube feeding. The acquisition lasted 1 second and the examination lasted approximately 15 minutes in total.

CT scan confirmed the diagnosis of isolated tracheoesophageal fistula (Figure 1). Coronal and axial views associated with virtual bronchoscopy showed a 4-mm tracheoesophageal fistula, localized on the right posterolateral side of the trachea and $1 \mathrm{~cm}$ above the carina.

The fistula was successfully closed by surgery through a small posterolateral thoracotomy in the fourth right intercostal space. A few days after surgery, an improvement of the respiratory state permitted extubation and the start of nasogastric tube feeding.

\section{Discussion}

Many noninvasive diagnostic methods have been used to prove a suspected H-type tracheoesophageal fistula, and bronchoscopy is traditionally the reference standard. However, these various modalities remain not entirely reliable, and fistula identification is generally insufficient. ${ }^{2}$ Recently, Blanco-Rodriguez and colleagues ${ }^{3}$ proposed to investigate $\mathrm{H}$-type tracheoesophageal fistula by catheterization, which has the disadvantage of being invasive with a low but definite complication rate. Our case demonstrates the valuable diagnostic utility of high-resolution CT scanning as an alternate noninvasive modality in this clinical situation. As compared with conventional bronchoscopy or catheterization, CT does not require any general anesthesia.

The improved spatial and temporal resolution of the new generation of scanners increases image quality as compared with previous outdated versions of scanners, ${ }^{4}$ thus facilitating assessment of small defects such as tracheoesophageal fistula. However, certain technique-related aspects must be satisfactory to allow the visualization of the fistula in routine practice. The major point is to introduce air into the trachea or into the esophageal during CT acquisition. Such a maneuver is important in optimizing the visualization of the fistula, which may be totally or partially closed by a valvelike mucosal flap or by a spasm of the muscular layer of the esophagus. $^{5}$

Investigation of an infant with a suspected H-type tracheoesophageal fistula includes 2 objectives. In addition to the diagnosis confirmation, accurate localization of the fistula is crucial, as this influences the approach to the subsequent surgical repair. ${ }^{5}$ Here, 64-slice CT depicted the fistula accurately during a rapid and safe examination. It also localized the exact topography of the defect, thus permitting planning of the surgery. In our case, surgery was performed appropriately with a small right-sided thoracic incision guided with CT results. 

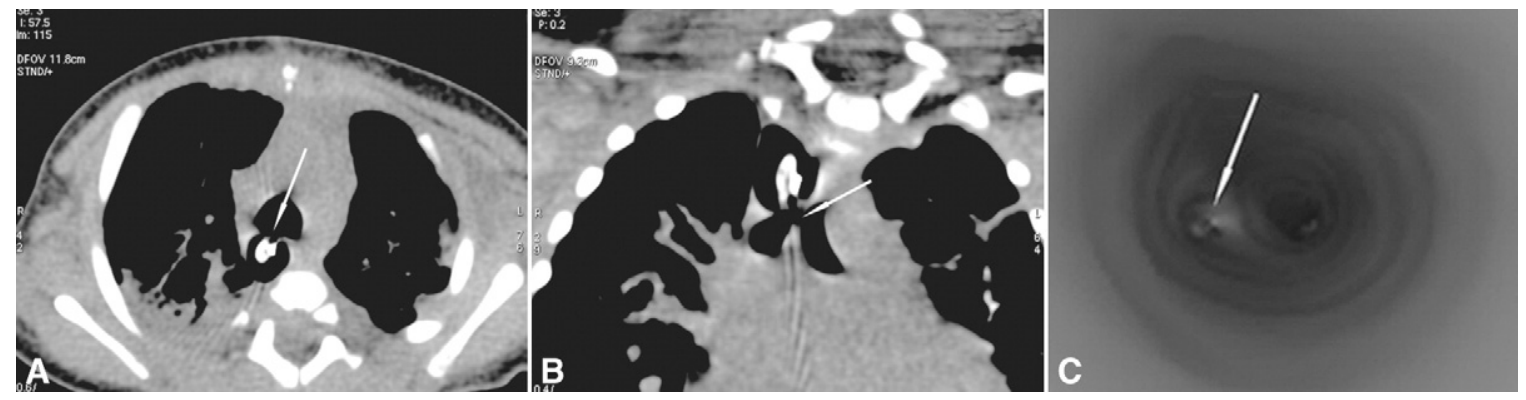

Figure 1. Chest CT with a 64-slice scanner. A, B, Axial and coronal sections of the thorax showing the fistula (arrow). Note the distension of the esophagus related to air insufflation, which enlarges the fistula, thus facilitating the diagnosis. C, Virtual bronchoscopy showing the fistula at the right posterolateral wall of the trachea (arrow).

In summary, the present case demonstrates the diagnostic utility of the new generations of multislice CT scanning in such an unstable clinical situation. When performed appropriately with air insufflation into the trachea or esophagus during image acquisition, 64-slice CT permits a rapid, safe, and accurate diagnosis of H-type tracheoesophageal fistula.

\section{References}

1. LaSalle AJ, Andrassy RJ, Ver Steeg K, Ratner I. Congenital tracheoesophageal fistula without esophageal atresia. J Thorac Cardiovasc Surg. 1979;78:583-8.
2. Ng J, Antao B, Bartram J, Raghavan A, Shawis R. Diagnostic difficulties in the management of H-type tracheoesophageal fistula. Acta Radiol. 2006;47:801-5.

3. Blanco-Rodriguez G, Penchyna-Grub J, Trujillo-Ponce A, NavaOcampo AA. Preoperative catheterization of H-type tracheoesophageal fistula to facilitate its localization and surgical correction. Eur J Pediatr Surg. 2006;16:14-7.

4. Fitoz S, Atasoy C, Yagmurlu A, Akyar S, Erden A, Dindar H. Threedimensional CT of congenital esophageal atresia and distal tracheoesophageal fistula in neonates: preliminary results. AJR Am J Roentgenol. 2000;175:1403-7.

5. Crabbe DC. Isolated tracheo-oesophageal fistula. Paediatr Respir Rev. 2003;4:74-8. 